\title{
Физические свойства (плотность, упругая анизотропия) образцов горных пород уранового рудопроявления Лицевское
}

\author{
Ильченко В.Л., Ниткина Е.А., Забавчик Н.И. \\ Геологический институт КНЦ РАН, Anamumbl,vadim@geoksc.apatity.ru
}

\begin{abstract}
Аннотация. Изучение физических свойств пород и их сравнение с данными радиометрических исследований по профилю на урановом рудопроявлении Лицевское показало наличие двух участков, на одном из которых максимальные значения упругой анизотропии совпадают с повышенной радиоактивностью пород, а на другом - обратное соотношение. Такое распределение, скорее всего, указывает на наличие двух временных этапов в формировании оруденения с разным распределением и формой нахождения урана в породах. Обнаруженная корреляция пространственного распределения показателя упругой анизотропии и радиологического фона подтверждает предполагаемое ранее наличие тектонических закономерностей и структурных предпосылок и определяет идеологию дальнейших исследований на предмет построения геолого-структурных моделей земной коры с благоприятными для формирования урановорудных объектов условиями.

Ключевые слова: физические свойства горных пород, плотность, упругая анизотропия, рудопроявление урана.
\end{abstract}

\section{Physical properties (density, elastic anisotropy) of rock samples of the Litsevskoe uranium ore occurrence}

\author{
Il'chenko V.L., Nitkina E.A., Zabavchik N.I. \\ Geological institute KSC RAS, Apatity,vadim@geoksc.apatity.ru
}

\begin{abstract}
The study of physical properties of rocks and their comparison with radiometric data along the profile on the Litsevskoye uranium ore occurrence showed the presence of two sites, at one of which the maximum values of elastic anisotropy coincide with the high radioactivity of rocks, and on the other - the correlation is inverse. This dependence, most likely, indicates the presence of two time stages in the formation of mineralization with different spreading and form of uranium allocation in rocks. The found correlation in spatial distribution of the elastic anisotropy index and radiological background confirms the previously assumed the presence of tectonic regularities and structural preconditions and determines the ideology of further research on the construction of geological and structural models of the Earth's crust favorable for the formation of uranium occurrences.
\end{abstract}

Key words: physical properties of rocks, density, elastic anisotropy, uranium ore occurrence.

\section{введение}

Данная статья посвящена изучению урановой рудоносности Лицевского района, где было обнаружено около 40 рудопроявлений (Савицкий и др., 1995, Казанский, Лобанов, 1996) и, таким образом, этот район представляется прекрасным полигоном для проведения работы. В статье представлены результаты изучения физических свойств горных пород (плотность, упругая анизотропия) из обнажений в пределах Лицевского уранового рудопроявления (самое крупное из обнаруженных в Печенга-Лицевской металлогенической области). Эта работа завершает серию исследований, проведённых нами в данном районе на ряде объектов (р/п Скальное, Дикое, Полярное, Береговое и др.) в периоды 2013-2015 и 2016-2018 гг. (тема НИР ГИ КНЦ РАН № 0231-2015-0006, программа Президиума РАН №19).

\section{Рудопроявление Лищевское}

Это рудопроявление открыто в 1962 году, после чего, в 1973-1974, оно разрабатывалось ПО «Невскгеология» с проведением геологических и геофизических исследований, бурения, расчисток и канав. Р/п Лицевское расположено на СВ экзоконтакте Лебяжинского массива, на пересечении Лицкого и Чептьяврскогов разломов, в мигматизированных гнейсах Кольской серии (рис. 1), смятых в субмеридиональные складки с падением крыльев 50-60. Эти складки пересекаются согласными и поперечными тектоническими разломами, заполненными катаклазитами и брекчиями, ино- 
гда с фрагментами конгломератов и аркозов (Савицкий и др., 1995). Следующими полевыми наблюдениями (Serov, 2011) здесь выявлено несколько типов аномалий, возможно отвечающих различным стадиям обогащения ураном.

1. Аномалии, связанные с мигматизацией (палеопротерозойские события), наблюдались во вмещающих гнейсах, представляющих метаосадки разной природы: биотитовые гнейсы, полевошпатовые гнейсы и кварциты. Они мигматизированы в разной степени. Например, в богатых биотитом гнейсах находятся свидетельства частичного плавления в виде лейкосом, которые имеют плавные контакты. Лейкосомы отсутствуют в обогащенных кварцем слоях гнейсов. Максимальная радиоактивность (до 1500 мкр/ч) связана здесь с дислоцированными биотитовыми гнейсами, со средним радиационным фоном $\approx 30-40$ мкр/ч. Радиоактивность вмещающих кварц-полевошпатовых гнейсов $<20$ мкр/ч.

2. Высокорадиоактивные аномалии наблюдались вдоль мелкозернистых мафитовых даек северо-западного простирания (345-350 ), секущей гнейсы Кольской серии. Они до 40 метров длиной и 0.2-2 м шириной и смещены СВ разломами. Контакты с вмещающими гнейсами рассланцованы, окислены и аномально радиоактивны 250-400 $(\max =1200)$ мкр/ч.

3. Третий тип аномальной радиоактивности связан с настурановыми жилами в кварцмусковитовых крупнозернистых жилах, секущих биотитовые гнейсы. Кварц-мусковитовые жилы сами не является радиоактивным, шириной 20-30 см и длиной 20 м. Они простираются к СВ $\left(60^{\circ}\right)$ при субвертикальном падении. Настурановые жилки имеют мощность до 2 см и радиоактивность более 3000 мкр/ч, находятся в центре жил и имеют ту же ориентацию.

Все перечисленные типы аномалий и их геолого-структурные признаки нахождения, в той или иной мере, наблюдались нами на изученном участке (рис. 1). Следует отметить, что подобные петрофизические работы - по сопоставлению упругой анизотропии образцов пород с их радиоактивностью - в Лицевском районе ранее не проводились.

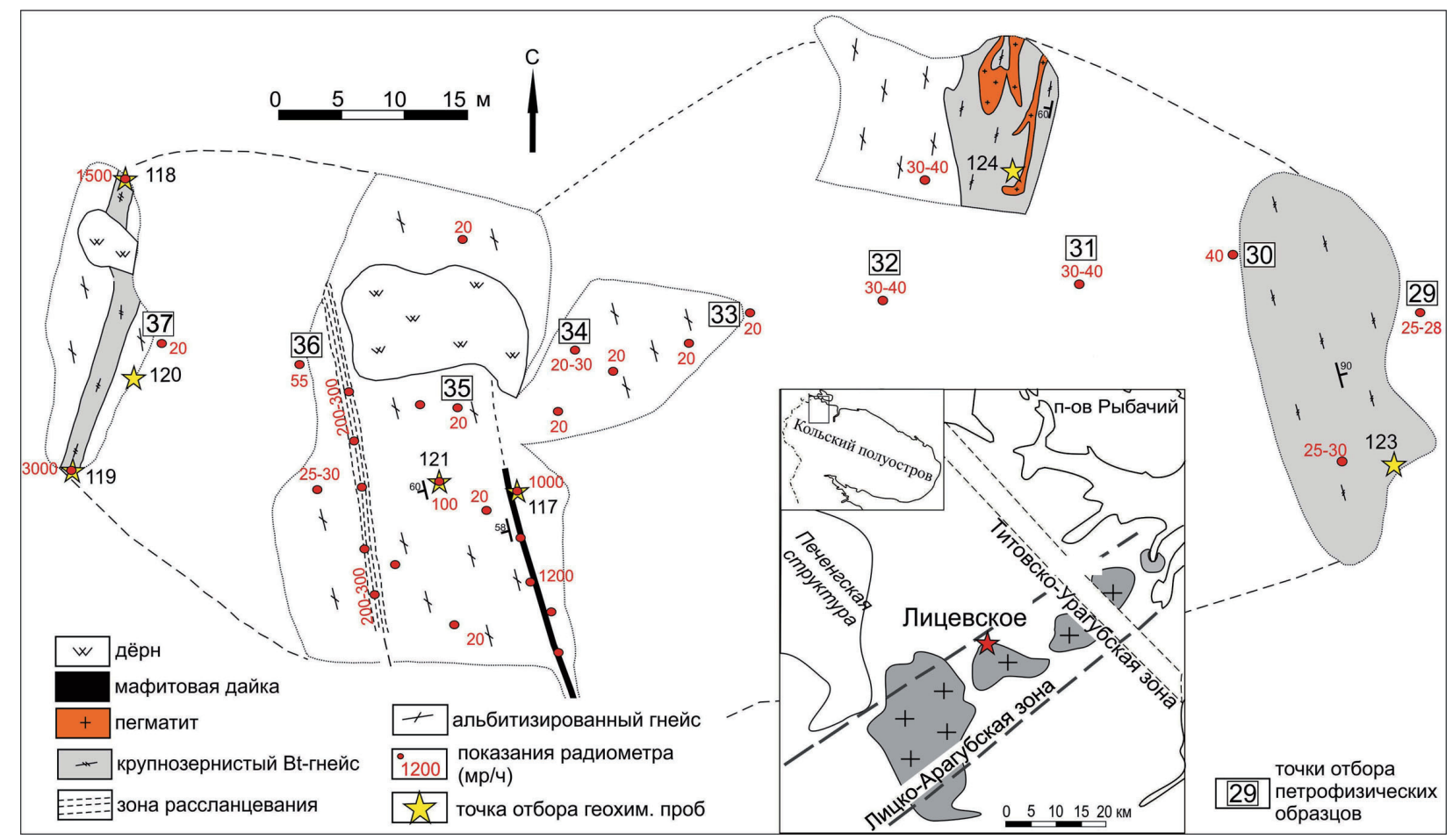

Рис. 1. Карта-схема расчисток с результатами радиометрии и точками отбора различных проб на изученном участке р/п Лицевское (авторы: Ниткина Е.А., Забавчик Н.И.).

Fig. 1. A sketch-map: results of radiometry and sampling points on the study area as a part of the Litsevskoye oreoccurrence (Nitkina E.A., Zabavchik N.I.). 


\section{Методика и результаты исследования}

Полевыми работами на р/п Лицевское (2018 г.) были обнаружены выходы коренных пород в расчистках (возможно, они сохранились с 70-х годов прошлого века) которые были закартированы авторами. Фоновые значения радиоактивности пород составляют 20 мкр/ч, установлены радиометрические аномалии до 3000 мкр/ч, на порядки превышающие фоновые значения (рис. 1). Из обнажений отобраны пробы на разные виды анализов, включая пространственно ориентированные образцы для определения физических свойств, всего 9 точек отбора, причём в двух точках (29 и 31) взято по 2 образца - с разной степенью мигматизации - для оценки влияния этой мигматизации на физические свойства пород. Шаг отбора петрофизических проб $\approx 10$ м. Порядок отбора проб аналогичен использованному на р/п Береговое (Ильченко и др., 2017). Петрография образцов изучена в шлифах.

Для проведения петрофизических измерений, из отобранных проб были выпилены образцы кубической формы (с сохранением их пространственной ориентировки), после чего грани кубиков были пронумерованы: нормали к граням 1 и 2 - указывают, соответственно, направления на север и восток, нормаль к грани 3 - вертикаль.

Таблица. Физические свойства образцов горных пород рудопроявления Лицевское.

Table. Physical properties of rock samples of the Litsevskoe ore occurrence.

\begin{tabular}{|c|c|c|c|c|c|c|c|}
\hline $\begin{array}{l}\text { № } \\
\text { Пп }\end{array}$ & $\begin{array}{c}\text { № } \\
\text { обр. }\end{array}$ & Горная порода & 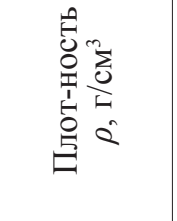 & $\begin{array}{c}\text { Скорость } \\
\text { продольных } \\
\text { волн (км/с): } \\
V_{l}, V_{2}, V_{3}\end{array}$ & $\begin{array}{l}V_{c p}, \\
\text { Км } / \mathrm{c} .\end{array}$ & $A, \%$ & 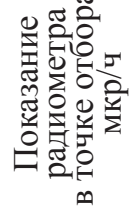 \\
\hline 1 & 2 & 3 & 4 & 5 & 6 & 7 & 8 \\
\hline 1 & $29-1$ & $\begin{array}{l}\text { Би-гнейс м/3, } \\
\text { мигматизированный }\end{array}$ & 2.62 & 3.783 .683 .51 & 3.66 & 5.28 & $25-28$ \\
\hline 2 & $29-2$ & $\begin{array}{l}\text { Би-гнейс м/3, } \\
\text { слабо-мигматизированный }\end{array}$ & $2.59(\underline{2.60})$ & 4.163 .964 .01 & $4.04(\underline{3.85})$ & $17.11(\underline{11.2})$ & $25-28$ \\
\hline 3 & 30 & $\begin{array}{l}\text { Би-гнейс, разнозернистый, } \\
\text { мигматизированный }\end{array}$ & 2.59 & 4.184 .084 .07 & 4.11 & 2.09 & 40 \\
\hline 4 & $31-1$ & Плагиогранит (пегматит) & 2.64 & 3.544 .003 .84 & 3.79 & 8.71 & $30-40$ \\
\hline 5 & $31-2$ & $\begin{array}{l}\text { Би-гнейс из контакта } \\
\text { с пегматитовой жилой }\end{array}$ & $2.66(\underline{2.65})$ & 4.364 .244 .08 & $4.23(\underline{4.01})$ & $19.51(\underline{14.1})$ & $30-40$ \\
\hline 6 & 32 & $\begin{array}{l}\text { Би-микроклиновый } \\
\text { гнейсогранит }\end{array}$ & 2.71 & 3.703 .773 .93 & 3.80 & 4.39 & $30-40$ \\
\hline 7 & 33 & Би-плагиогнейсогранит с/з & 2.63 & 3.993 .893 .71 & 3.86 & 5.17 & 20 \\
\hline 8 & 34 & Би-плагиогнейсогранит, м-с/3 & 2.54 & 3.914 .494 .01 & 4.14 & 10.59 & $20-30$ \\
\hline 9 & 35 & $\begin{array}{l}\text { Би-плагиогранитогнейс с-м/3, } \\
\text { мигматизированный }\end{array}$ & 2.56 & 4.224 .203 .97 & 4.13 & 4.76 & 20 \\
\hline 10 & 36 & $\begin{array}{l}\text { Би-плагиогранитогнейс с-м/3, } \\
\text { мигматизированный }\end{array}$ & 2.64 & 3.853 .713 .37 & 3.64 & 10.05 & $50-60$ \\
\hline 11 & 37 & $\begin{array}{l}\text { Би-плагиогранитогнейс с-м/3, } \\
\text { мигматизированный }\end{array}$ & 2.60 & 4.233 .774 .07 & 4.02 & 8.22 & 20 \\
\hline
\end{tabular}

В колонках 4, 6, 7 в скобках (№№ 2 и 5) даны средние арифметические значения для «двойных» проб.

Скорость распространения продольных волн $\mathrm{V}_{\text {п }}$ измерялась в трёх направлениях куба $(1,2,3)$ с помощью ультразвукового прибора ГСП УК-10ПМС. 
Коэффициент анизотропии $A$ образцов вычислен из скоростей распространения в образцах ультразвуковых продольных волн $\left(\mathrm{V}_{1}, \mathrm{~V}_{2}, \mathrm{~V}_{3}\right)$, в трёх ортогональных направлениях, по формуле:

$$
A=1 / V_{c p} \times\left(\left(V_{1}-V_{c p}\right)^{2}+\left(V_{2}-V_{c p}\right)^{2}+\left(V_{3}-V_{c p}\right)^{2}\right)^{0.5} \times 100 \%
$$

где $V_{c p}=\left(V_{1}+V_{2}+V_{3}\right) / 3-$ средняя скорость распространения продольных волн в образце. Плотность $(\rho)$ образцов измерена методом Архимеда.

Все результаты измерений и расчётов представлены в таблице; данные о плотности ( $\rho)$, средняя скорость распространения продольных волн $\left(V_{c p}\right)$, показатель упругой анизотропии $(A)$ и показания радиометра в точках отбора образцов - вынесены на график (рис. 2).

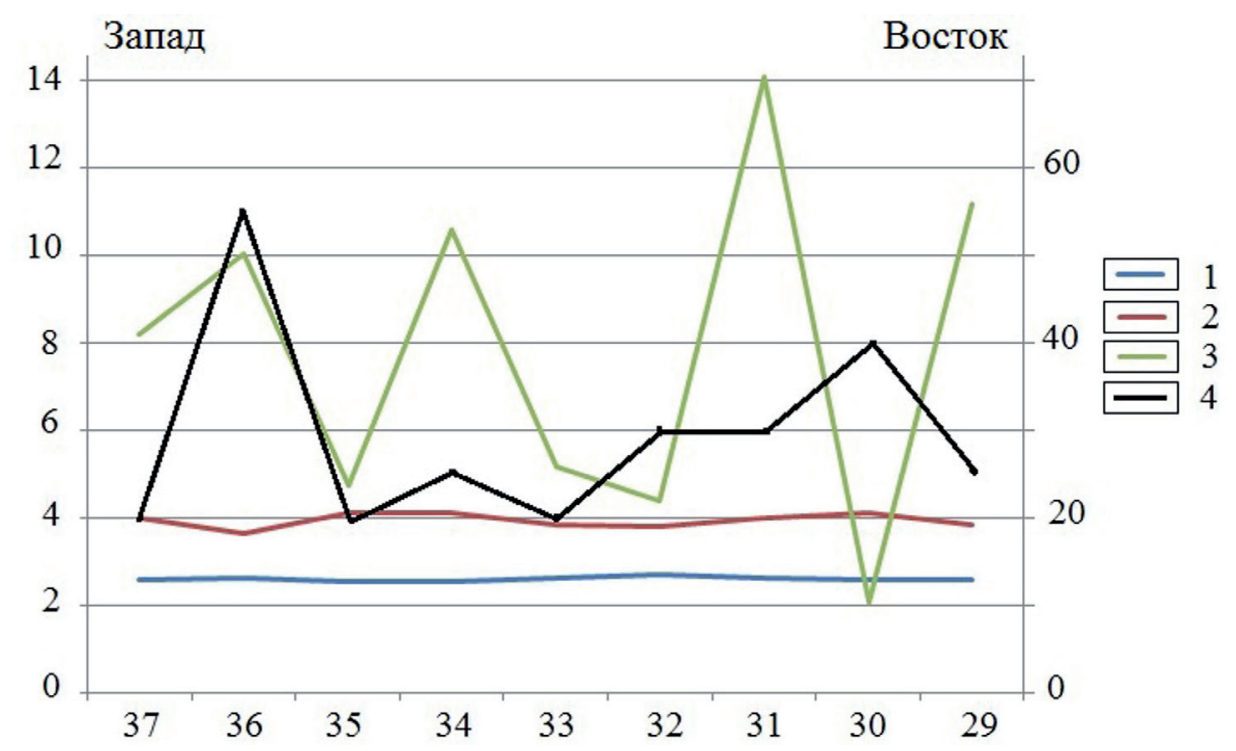

Рис. 2. Физические свойства образцов (по горизонтали - их номера) вдоль профиля через участок работ.

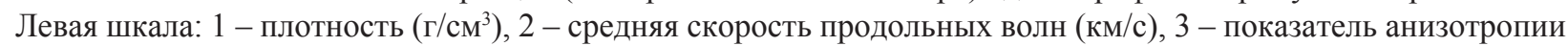
(\%); правая шкала: 4 - радиоактивный фон (мкр/ч).

Fig. 2. Physical properties of the samples (horizontal - their numbers) along the profile through the work area.

Left scale: 1 - density $\left(\mathrm{g} / \mathrm{cm}^{3}\right), 2$ - average velocity of longitudinal waves $(\mathrm{km} / \mathrm{s}), 3$ - anisotropy index $(\%)$; right scale: 4 - radioactivity $(\mathrm{mkr} / \mathrm{h})$.

\section{Обсуждение результатов}

Все образцы исследованной коллекции, петрографически, относятся к гранитоидам или породам кислого состава, а их плотность находится в соответствии со справочными данными $2.65 \pm 0.1$ г $\mathrm{cm}^{3}$ (Науки..., 1969). При сравнении свойств парных образцов, выпиленных из одного «куска» горной породы (проба № 29: кубики 29-1 и 29-2, проба № 31: кубики 31-1 и 31-2) было установлено, что изменения пород в итоге их (пусть частичного) переплавления (к развитию мигматитов и пегматитов) «статистически незначимо» (Савицкий, 1985) меняют первичные упругие свойства $\left(V_{c p}\right)$ и плотность пород, но, при этом, способны приводить к весьма заметным вариациям их показателя упругой анизотропии. Частичное плавление пород (высокая температура) «залечивает» ту анизотропную систему трещин, чьё наличие и обусловливает эффект упругой анизотропии горных пород (в принципе).

Установленные «волнообразные» вариации упругой анизотропии $\left(A_{\rho}\right)$ в образцах вдоль профиля (рис. 2), как и вариации средней скорости распространения продольных волн, во многом повторяют результаты аналогичных измерений, проведённых нами ранее на ряде других объектов Печенга-Лицевского района (Ильченко и др., 2017 и ссылки там).

Анализ вариаций вдоль профиля показателя упругой анизотропии и радиоактивности пород позволяет сделать вывод о смене каких-то динамических условий, с «переломом» в их тенденциях 
где-то между точек отбора проб № 32 и № 33 (с востока на запад). Для показателя анизотропии - это постепенное снижение «амплитуды волн» (на запад), для радиационного фона (учитывая его площадные значения, см. рис. 1) - наоборот: происходит повышение его «амплитуды». Причём, продвигаясь с востока на запад, до точки перелома (32/33), «волны» анизотропии и радиоактивности выступают «в противофазе» (радиоактивный фон растёт - показатель анизотропии падает и наоборот), после перелома тенденции к изменениям в этих параметрах (анизотропия и радиоактивность) ведут себя уже вполне «синфазно» (рис. 2).

Описанную выше ситуацию можно объяснить следующим образом: «противофазная» (восточная) и «синфазная» (западная) половины профиля трассируют блоки с U-оруденением различной природы (генераций), что подтверждает гипотезу (Serov, 2011). В восточной части уран - в форме уранил-ионов - концентрируется в межслоевых пространствах слоистых силикатов (биотит в биотитовых гнейсах) в результате кристаллизации расплава пегматитов и мигматитов, более стойких к выветриванию и обладающих пониженными показателями упругой анизотропии. В западной же части рудопроявления преобладает уран в минеральной форме (настуран-уранинит) - включения в сульфидах - (приконтактовые зоны даек основного состава) и жилки настурана в кварцевых жилах (Савицкий и др., 1995), развивавшихся по упруго анизотропным (и сильно трещиноватым) породным зонам путём осаждения рудного вещества из гидротермальных растворов, чья температура была заметно ниже температуры плавления пород при формировании мигматитов и пегматитов), предположительно, на заключительном (PZ) этапе формирования этого уранового рудопроявления.

\section{Выводы}

Самым интересным результатом проведённого исследования являются волнообразные вариации в распределении показателя упругой анизотропии $A$ в образцах вдоль профиля, что повторяет итоги аналогичных измерений, проведённых на других урановых объектах Печенга-Лицевского района. Обнаружено совпадение экстремальных значений результатов радиометрии (те же волнообразные вариации) с экстремальными значениями показателя упругой анизотропии, причём профиль пересекает два участка с разными типами такого рода совпадений: в противофазе и синфазное, что предполагает наличие двух разных этапов в формировании данного оруденения.

Обнаруженное совпадение в волновом пространственном распределении показателя упругой анизотропии и радиологического фона подтверждает предполагаемое ранее наличие закономерностей в тектонике с предопределением структурных предпосылок и определяет идеологию дальнейших исследований на предмет построения геолого-структурных моделей земной коры с благоприятными для формирования урановорудных объектов условиями.

Работа выполнена в рамках Госзадания ГИ КНЦ РАН, тема НИР № 0226-2019-0052.

\section{Литература}

1. Ильченко В.Л., Самигулин Р.Р., Каулина Т.В. Вариации упругих свойств пород урановых рудопроявлений (рудопроявление Береговое, Лицевский рудный район, Кольский регион) // Труды Ферсмановской научной сессии ГИ КНЦ РАН. 2017. № 14. С. 103-104.

2. Казанский В.И., Лобанов К.В. О границах и металлогении Печенгского рудного района //Геология рудных месторождений. 1996. № 1. С.103-109.

3. Науки о Земле. Т. 21. Пер. с англ. Справочник физических констант горных пород. Ред.: Г.Д. Афанасьев, Б.П. Беликов, М.П. Воларович. М. Изд-во: МИР. 1969. 544 с.

4. Савицкий А.В. Результаты петрофизических исследований пород разломов фундамента древних платформ / Петрофизические исследования на щитах и платформах. Апатиты. Изд-во: КФАН СССР. 1984. C. $109-111$.

5. Савицкий А.В., Громов Ю.А., Мельников Е.В., Шариков П.И. Урановое оруденение Лицевского района на Кольском полуострове (Россия) // Геология рудных месторождений. 1995. № 5. С. 403-416.

6. Serov L. Métallogenèse de l'uranium dans la région de Litsa (Péninsule de Kola, Russie). Docteur de l'Université Henry Poincaré (en géosciences). Soutenance publique le 24 juin 2011. Nancy. France. 166 p. 